\title{
Photocatalytic Decolourization of Direct Yellow 9 on Titanium and Zinc Oxides
}

\author{
Elżbieta Regulska, Diana Małgorzata Bruś, and Joanna Karpińska
}

Institute of Chemistry, University of Bialystok, Hurtowa 1, 15-399 Bialystok, Poland

Correspondence should be addressed to Elżbieta Regulska; e.regulska@uwb.edu.pl

Received 5 July 2013; Accepted 31 July 2013

Academic Editor: Mika Sillanpaa

Copyright (C) 2013 Elżbieta Regulska et al. This is an open access article distributed under the Creative Commons Attribution License, which permits unrestricted use, distribution, and reproduction in any medium, provided the original work is properly cited.

\begin{abstract}
The photodecolourization of Direct Yellow 9, a member of the group of azo dyes which are commonly used in the various branches of the industry, was investigated. The photostability of this dye was not previously examined. Photocatalytic degradation method was evaluated. Solar simulated light $\left(E=500 \mathrm{~W} / \mathrm{m}^{2}\right)$, titanium dioxide, and zinc oxide were used as irradiation source and photocatalysts, respectively. Kinetic studies were performed on a basis of a spectrophotometric method. Degradation efficiency was assessed by applying high performance liquid chromatography. Disappearance of a dye from titanium dioxide and zinc oxide surfaces after degradation was confirmed by thermogravimetry and Raman microscopy. Direct Yellow 9 was found to undergo the photodegradation with approximately two times higher efficiency when zinc oxide was applied in comparison with titanium dioxide. A simple and promising way to apply the photocatalytic removal of Direct Yellow 9 in titanium dioxide and zinc oxide suspensions was presented.
\end{abstract}

\section{Introduction}

Wastewater from industry contains various organic compounds such as dyes, surfactants, excipients, and many others. Among all of them dyes are widely used in various branches of the textile industry, cosmetics, and paper production, in food technology, and so forth [1]. The amount of dyes produced in the world is estimated to be over 10,000 tons per year. Exact data on the quantity of dyes discharged in the environment are not available. However, it is assumed that a loss of $1-2 \%$ in production and $1-10 \%$ loss in use are a fair estimate [2].

Those substances enter the ecosystem modifying the environment and becoming a major threat for all forms of life [3]. Removing dyes is more important than colorless compounds, because even at a low concentration (below $1 \mathrm{ppm}$ ), they can change the color and the transparency of water [4]. Their presence in an aqueous environment decreases the sunlight penetration and consequently reduces an activity of a photosynthesis and a solubility of gases [5]. Furthermore, some dyes are toxic or potentially carcinogenic. In this connection, it is necessary to protect the environment against that pollution and decontaminate the sewage treatment plant effluents or industrial aquatic waste. Therefore, there is a necessity to apply efficient degradation techniques by factories and industrial plants where dyes are being created or applied during manufacturing process [6].

Traditional techniques such as biodegradation, adsorption, coagulation, reverse osmosis, and the others are ineffective for complete destruction of dyes [7]. Biodegradation, for instance, does not work efficiently because of a high resistance of dye molecules. Therefore, it can lead to the generation of hazardous aromatic amines [4]. Most of above-mentioned methods are nondestructive. They only transfer contaminations from solution to another phase, thus producing a large amount of sludge with a secondary pollution, which is difficult to remove [8]. Therefore, it is essential to consider other, more efficient and less invasive methods [9].

Recently, Advanced Oxidation Processes (AOPs) seem to be an alternative to conventional treatment and can be successfully used to destruct dyes and other organic substances [10]. AOPs have employed photocatalysts, Fenton reagents, ozone, hydrogen peroxide, and ultraviolet or solar light, separately or combining some of them [11]. The mechanism is based on a generation of hydroxyl radicals which have one of the highest oxidative potential $\left(E_{0}=+2.8 \mathrm{~V}\right)$ [12]. Hence, 


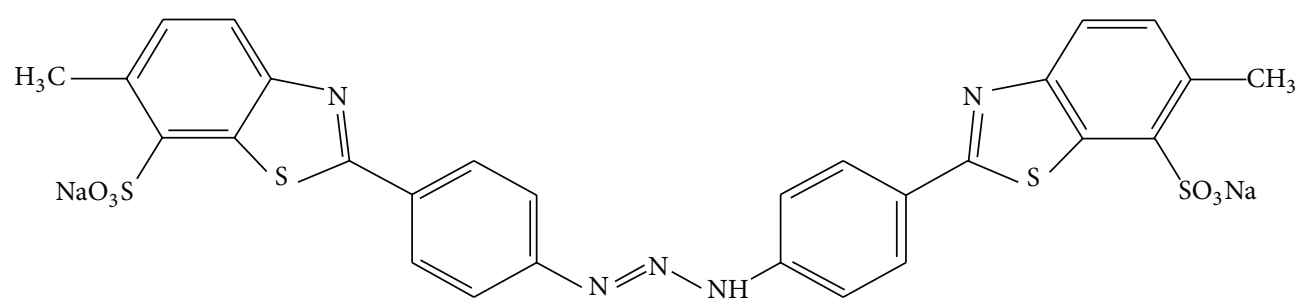

Scheme 1: Chemical structure of Direct Yellow 9.

they are useful in a complete mineralization of organic water pollutants to carbon dioxide, water, and inorganic anions [13]. Among AOPs, heterogeneous photocatalysis with the usage of a semiconductor as a photocatalyst is a promising method for color removal from water [14].

In performed studies two semiconductors, namely, $\mathrm{TiO}_{2}$ and $\mathrm{ZnO}$, were used. Both of them are cheap, nontoxic, photochemically stable, environmentally friendly [13], and water insoluble [15], and they have similar energy of band gaps $[16,17]$. Those catalysts were applied in a photodegradation of Direct Yellow 9 (DY9, Scheme 1), also known as Titan Yellow, Clayton Yellow, and Thiazole Yellow G, a dye which photostability was not previously examined.

DY9 is used as a stain and fluorescent indicator in microscopy. What is more, it was successfully applied in analytical methods of magnesium determination in serum [18], tissue [19], plant material [20] and rocks [21]. It was also used for estimation of beryllium in waste water [22], commercial aminoglycoside antibiotics in serum samples [23], and tetracycline antibiotics in chook serum and human urine samples [24].

\section{Materials and Methods}

2.1. Materials. $\mathrm{TiO}_{2}$ (anatase, Sigma-Aldrich) and $\mathrm{ZnO}$ (Sigma-Aldrich), Direct Yellow 9 (Riedel-de-Haën AG), and ammonium reineckate- $\mathrm{NH}_{4}\left[\mathrm{Cr}(\mathrm{SCN})_{4}\left(\mathrm{NH}_{3}\right)_{2}\right] \cdot \mathrm{H}_{2} \mathrm{O}(\mathrm{BDH}$ Chemicals Ltd, England) were used. All above-mentioned chemicals were analytical grade reagents and used without further treatment. HPLC-grade acetonitrile was purchased from Merck. All solutions were prepared using deionized water, which was obtained by Polwater apparatus.

2.2. Apparatus. UV spectrophotometric analyses were performed with a HITACHI U-2800A UV-VIS spectrophotometer equipped with a double monochromator and double beam optical system (190-700 nm). UV studies were done using $1 \mathrm{~cm}$ quartz cell. Optical density was recorded in the range of $190-560 \mathrm{~nm}$, and the maximum absorption wavelength experimentally registered at $\lambda=408 \mathrm{~nm}$ was used for the calibration curve and further DY 9 concentration measurements.

Photolytic as well as photocatalytic degradation experiments were carried out in a solar simulator apparatus, namely SUNTEST CPS+ (ATLAS, USA). The photon flux of solar simulated radiation was measured by chemical methodReinecke's salt actinometer [25]. The photon flux of solar simulated light of $500 \mathrm{~W} / \mathrm{m}^{2}$ was $2.32 \times 10^{-6}$ Einstein/s.
A Renishaw Raman InVia Microscope equipped with a high sensitivity ultralow noise CCD detector was employed. The radiation from an argon ion laser $(785 \mathrm{~nm})$ at an incident power of $1.15 \mathrm{~mW}$ was used as the excitation source. Raman spectra were acquired with 3 accumulations of $10 \mathrm{~s}$ each, $2400 \mathrm{~L} / \mathrm{mm}$ grating, and using 20x objective.

Differential scanning calorimetric (DSC) and thermogravimetric (TGA) analyses were performed by a Thermal Analyzer TGA/DSC 1 (METTLER TOLEDO) with a heating rate of $15^{\circ} \mathrm{C} / \mathrm{min}$ under nitrogen environment with flow rate $=20 \mathrm{~mL} / \mathrm{min}$. All runs were carried out from $25^{\circ} \mathrm{C}$ to $1550^{\circ} \mathrm{C}$. The measurements were made in alumina crucibles with lids.

The chromatographic experiments with HPLC-UV system were carried out on a Thermo Separation liquid chromatograph. The chromatographic column Waters Spherisorb ODS-2 $150 \mathrm{~mm} \times 4.6 \mathrm{~mm}$ packed with $5 \mu \mathrm{m}$ particle size was used. Separation was achieved using an isocratic method. The mobile phase consisted of an acetonitrile: water $(60: 40 \mathrm{v} / \mathrm{v})$. The flow rate of the mobile phase was $1 \mathrm{~mL} / \mathrm{min}$, and the injection volume was $100 \mu \mathrm{L}$. The column was maintained at a room temperature. The eluent was monitored at $322 \mathrm{~nm}$.

\subsection{Photocatalytic Degradation Experiment}

2.3.1. Direct Photolysis. All experiments were done using $50 \mathrm{~mL}$ glass cell. $20 \mathrm{~mL}$ of the working solution of Direct Yellow 9 (DY9) at the concentration $80 \mu \mathrm{mol} \cdot \mathrm{L}^{-1}$ was subjected to irradiation by Solar Light simulator SUNTEST CPS ${ }^{+}$, ATLAS USA emitting radiation in the range $300-800 \mathrm{~nm}$ with intensity $500 \mathrm{~W} \mathrm{~m}^{-2}$ for two hours. $\mathrm{pH}$ of aqueous solution was adjusted with $0.1 \mathrm{~mol} \cdot \mathrm{L}^{-1} \mathrm{H}_{2} \mathrm{SO}_{4}$ or $0.1 \mathrm{~mol} \cdot \mathrm{L}^{-1}$ $\mathrm{NaOH}$. pH was measured with an Elmetron CP-501 pHmeter (produced by ELMETRON, Poland) equipped with a pH-electrode EPS-1 (ELMETRON, Poland). The temperature of samples room was adjusted to $35^{\circ} \mathrm{C}$. The spectra of irradiated solutions were recorded every $15 \mathrm{~min}$.

All tested samples were prepared in triplicate.

The photocatalytic degradation experiments were performed in $50 \mathrm{~mL}$ glass cell. The reaction mixture consisted of $20 \mathrm{~mL}$ of Direct Yellow 9 (DY9) sample $\left(80 \mu \mathrm{mol} \cdot \mathrm{L}^{-1}\right)$ and a photocatalyst $\left(1.5 \mathrm{~g} \cdot \mathrm{L}^{-1}\right)$. Prior the irradiation the dyecatalyst suspension was kept in the dark with stirring for 1 hour to ensure an adsorption-desorption equilibrium. To determine the DY9 degradation, the samples were collected at regular intervals $(15 \mathrm{~min})$ and centrifuged to remove the photocatalyst. 


\section{Results and Discussion}

3.1. The Primary Studies. As presented in Figure 1, the absorption spectra of DY9 differ when registered at different pH. DY9 spectrum in neutral environment is characterized by three bands, namely, at 202, 322, and $408 \mathrm{~nm}$. The band at $408 \mathrm{~nm}$ was applied for monitoring changes in DY9 concentration. It was observed that the shape and intensity of absorption bands depend on $\mathrm{pH}$ of solution. The native $\mathrm{pH}$ of aqueous solution of Direct Yellow 9 is 5.8. The increase in $\mathrm{pH}$ causes the increase in intensity of the band at $408 \mathrm{~nm}$ and decrease of bands intensity at 202 and $322 \mathrm{~nm}$. The lowering in $\mathrm{pH}$ causes reduction of intensity of all peaks and small bathochromic shift of the band at analytical wavelength. The stability of examined dye under simulated solar radiation was checked. For this purpose solutions of DY9 at pH 2, 7, and 10 were prepared and subjected to irradiation in solar simulator chamber for 2 hours. The first-rate model of kinetics was assumed. The acquired experimental data showed that studied dye is photochemically stable. The changes in its concentration at $\mathrm{pH} 7$ and 10 were negligible. The observed rate of reactions was $4 \times 10^{4} \mathrm{~min}^{-1}$. Slight reduction of DY9 concentration was observed at acidic $\mathrm{pH}$. The observed rate of this process was $3.2 \times 10^{-3} \mathrm{~min}^{-1}$.

3.2. Adsorption Studies. Adsorption studies were performed in order to estimate whether the adsorption of DY9 on the $\mathrm{TiO}_{2}$ and $\mathrm{ZnO}$ surface has physical or chemical character. It is well known that physisorption is well described by the Freundlich isotherm (1), whereas chemisorption by the Langmuir isotherm (2) is as follows:

$$
\begin{gathered}
\frac{x}{m}=k C_{t}^{1 / n}, \\
\frac{x}{m}=\frac{(x / m)_{\infty} k C}{1+k C},
\end{gathered}
$$

where $x$ is mass of DY9 adsorbed on the photocatalyst surface, $m$ is mass of $\mathrm{TiO}_{2} / \mathrm{ZnO}, C_{t}$ is concentration of DY 9 in the solution after $1 \mathrm{~h}$ of adsorption in the dark, $k$ is adsorption constant, $n$ is constant characteristic for an exact system.

Experimental data were fitted to the plot of $x / m$ versus $C_{t}$ and presented in Figure 2. Relationships shown in Figure 3(a) $\left(\mathrm{TiO}_{2}\right)$ and Figure 3(b) $(\mathrm{ZnO})$ are typical for the adsorption process. It is clear that with an increase in DY9 concentration, there is also, to some point, an increase in mass of dye which is adsorbed on the photocatalyst surface. However, after crossing enough high concentration value, no more adsorbate is able to be adsorbed on the adsorbent surface. Unfortunately, presented charts do not directly indicate the adequate adsorption character. In order to determine that, linear relationship is crucial. With the aim of doing that, the linear transformations of (1) and (2) were expressed by the following equations:

$$
\begin{gathered}
\log \frac{x}{m}=\log k+\frac{1}{n} \log C_{t}, \\
\frac{C_{t}}{(x / m)}=\frac{1}{k(x / m)_{\infty}}+\frac{C_{t}}{(x / m)_{\infty}} .
\end{gathered}
$$

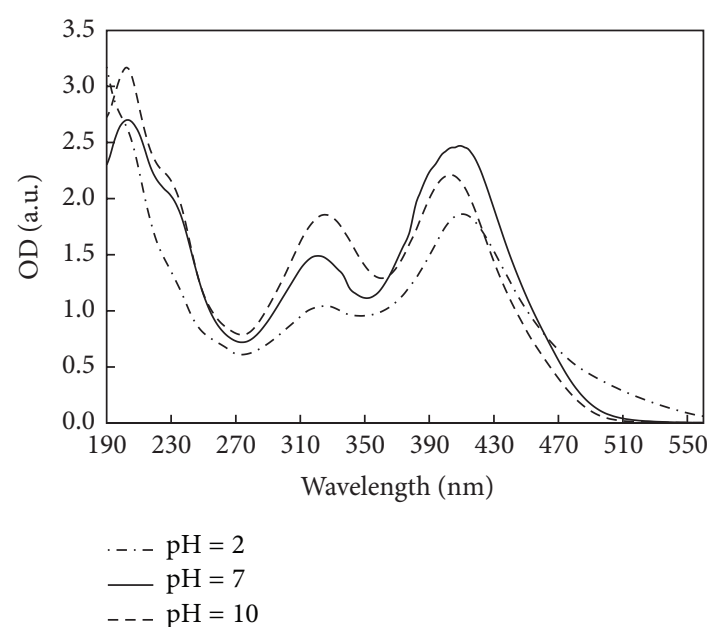

FIGURE 1: Absorption spectra of aqueous solution of DY9 (80 $\left.\mu \mathrm{mol} \cdot \mathrm{L}^{-1}\right)$ at different $\mathrm{pH}$.

To established the adsorption character, experimental data were fitted to both of previous equations (3) and shown in Figure 2. On the basis of the higher value of correlation coefficients in case of Langmuir isotherm $\left(R^{2}=0,9926\right.$ for $\mathrm{TiO}_{2}, R^{2}=0,9784$ for $\mathrm{ZnO}$ ) in comparison with those obtained from Freundlich isotherm $\left(R^{2}=0,9910\right.$ for $\mathrm{TiO}_{2}$, $R^{2}=0,9389$ for $\mathrm{ZnO}$ ), the chemical character of DY9 adsorption on the both photocatalysts surface was established.

3.3. Photodegradation Studies. Photodegradation of DY9 was monitored spectrophotometrically. According to Figure 3, UV-Vis spectra taken during irradiation in the presence of both photocatalysts clearly depict the decreasing concentration of examined dye, which is due to its decomposition. On the basis of these studies the kinetics of the photocatalytic degradation was evaluated (described in Section 3.4).

Raman microscopy, thermogravimetry, and HPLC analyses were applied to reveal whether the photodegradation with the usage of $\mathrm{TiO}_{2}$ or $\mathrm{ZnO}$ is sufficiently destructive method to degrade DY9. Therefore, data before and after irradiation experiment ( 2 hours of irradiation) were presented.

Raman spectra were registered to compare the adsorbed species present on the photocatalyst surface. Figure 4 shows the spectra of the examined samples taken by Raman microscope. In case of both semiconductors, after adsorption, without exposition to the solar light, in the region of 1100$1700 \mathrm{~cm}^{-1}$ certain bands appear. While after photodegradation almost no bands indicating DY9 presence on the surface can be seen. Moreover, on the images (taken by Raman microscope) of the semiconductors surface, yellowish spots present after adsorption were not found after irradiation treatment. Those results indicate that DY9 is adsorbed on the surface of both applied photocatalysts, and what is more, that the complete degradation of DY9 takes place.

In order to confirm Raman spectroscopic results thermochemical characterization was performed. Thermogravimetric curves were presented in Figure 5. They indicate 


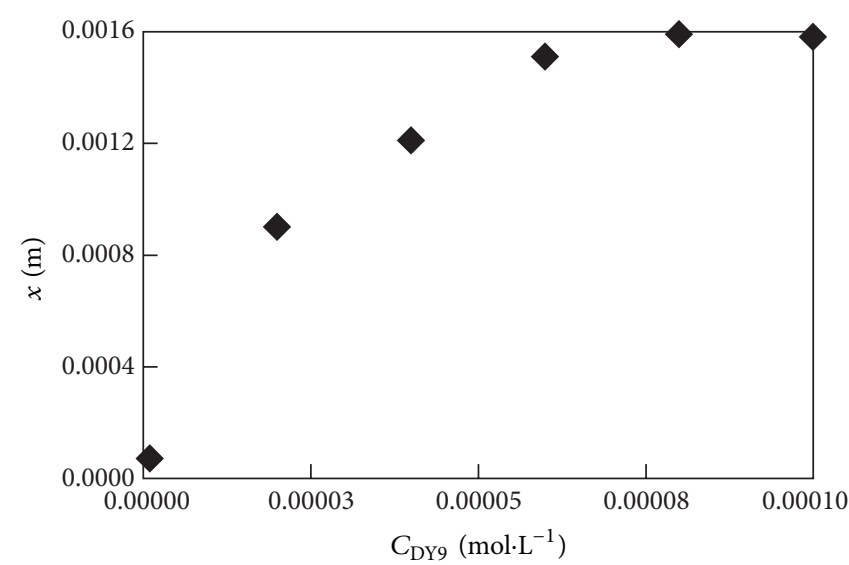

(A)

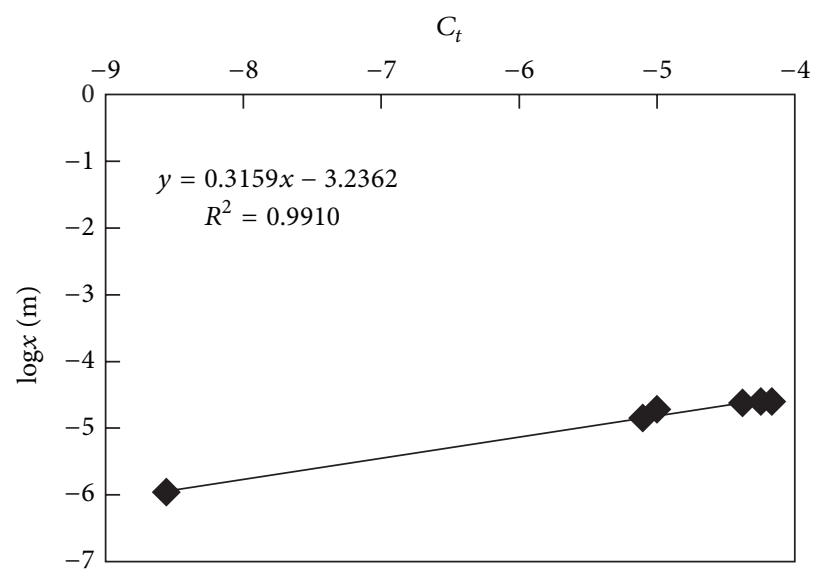

(B)

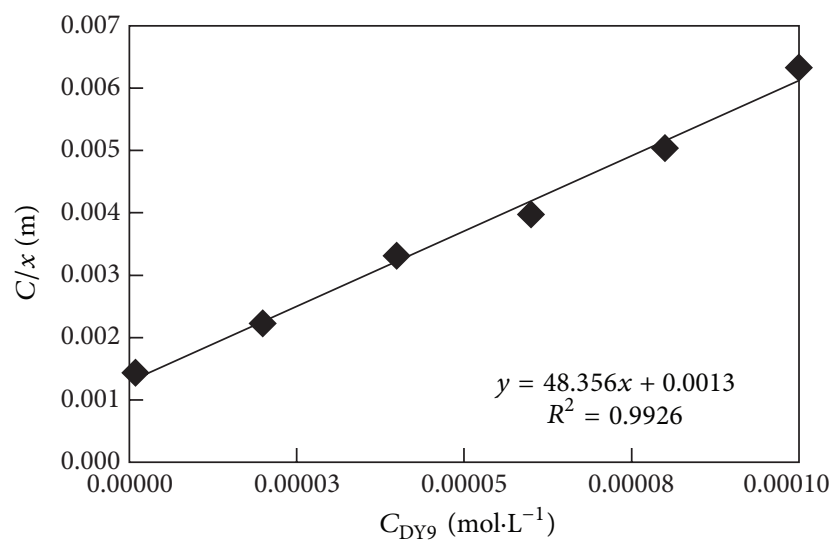

(C)

(a)

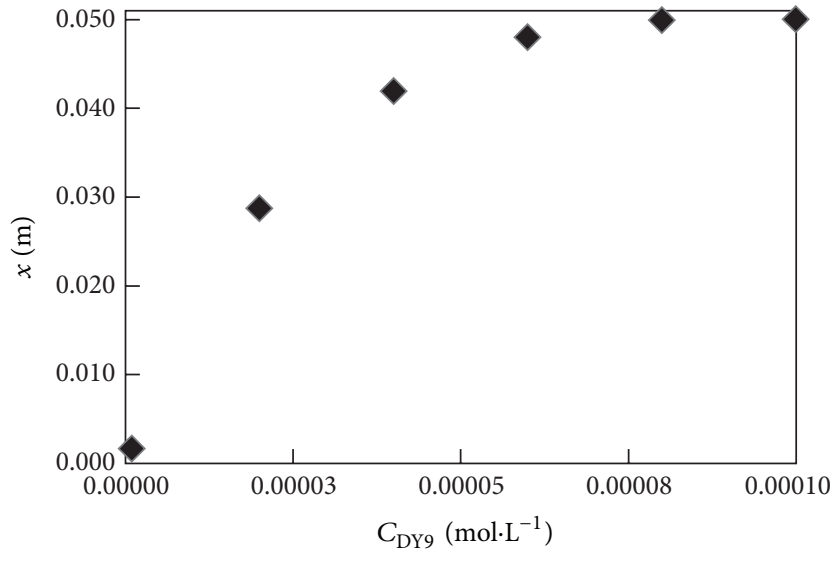

(A)

$C_{t}$

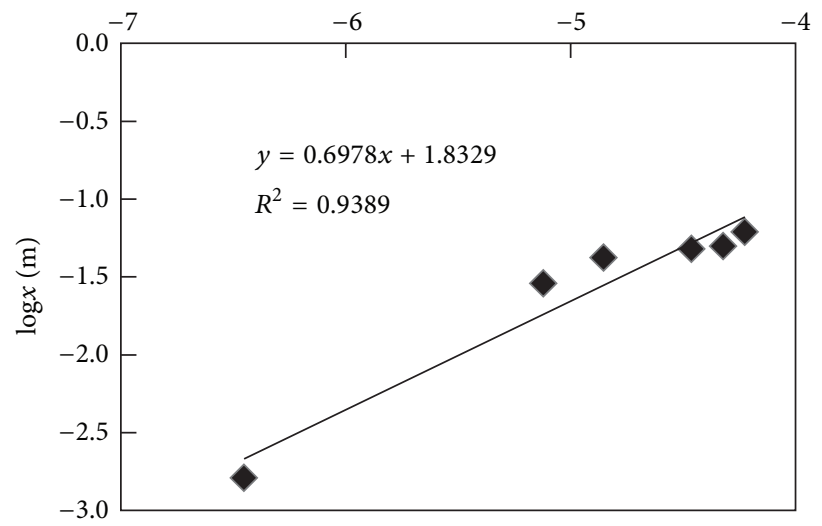

(B)

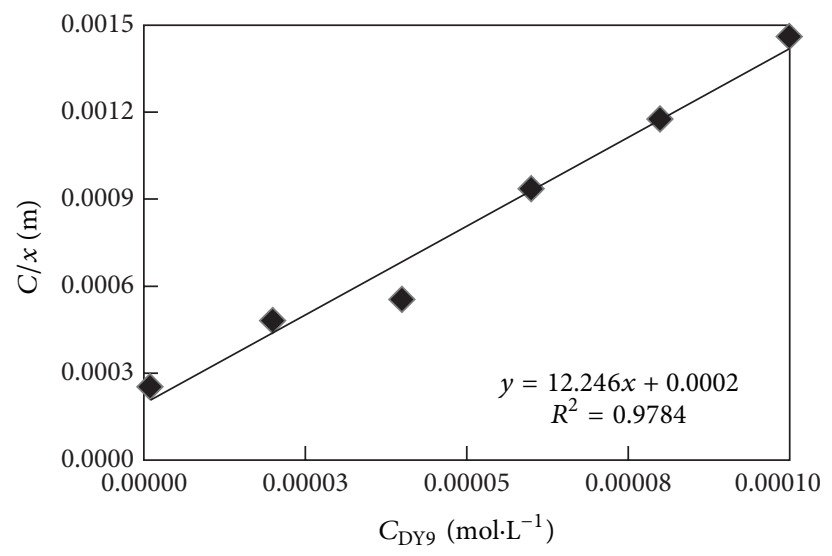

(C)

(b)

FIGURE 2: Isotherms of the adsorption process of $\mathrm{DY} 9$ on the $\mathrm{TiO}_{2}$ (a.A) and $\mathrm{ZnO}$ (b.A) surface. Linear Freundlich ((a.B) and (b.B) for TiO 2 and $\mathrm{ZnO}$, resp.) and Langmuir ((a.C) and (b.C) for $\mathrm{TiO}_{2}$ and $\mathrm{ZnO}$, resp.) adsorption isotherm of DY9 on the photocatalyst surface.

that after degradation a weight loss on the photocatalysts surface took place. This is due to the decomposition of a dye. This observation is true for both of used semiconductors. However, a slightly bigger weight loss was observed when $\mathrm{TiO}_{2}(2.2 \%)$ was applied in comparison with $\mathrm{ZnO}(1.9 \%)$.
It could be influenced by the higher adsorption of DY9 on the $\mathrm{TiO}_{2}$ surface (8\%) than on $\mathrm{ZnO}(5.8 \%)$.

HPLC analyses (Figure 6) were performed in order to study whether any intermediate products after photocatalytic degradation of DY9 remained in the solution. It was found 


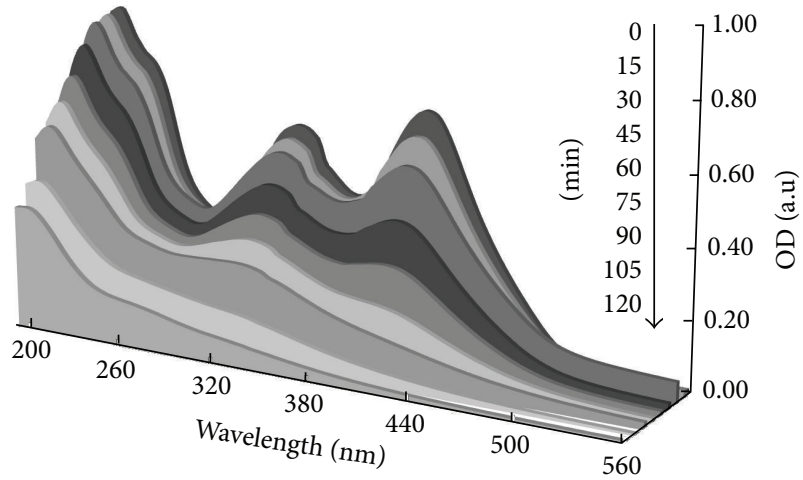

(a)

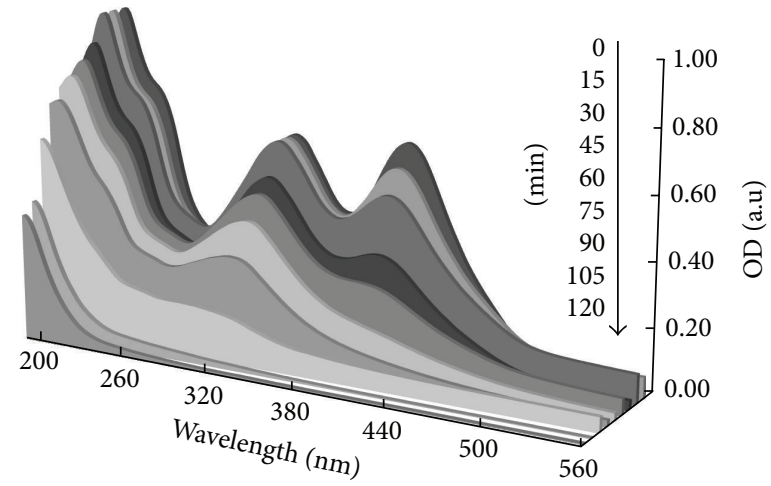

(b)

FIgURE 3: Normalized UV-Vis spectra of DY9 with the increasing irradiation time during application of $\mathrm{TiO}_{2}$ (a) and $\mathrm{ZnO}$ (b) as photocatalysts.

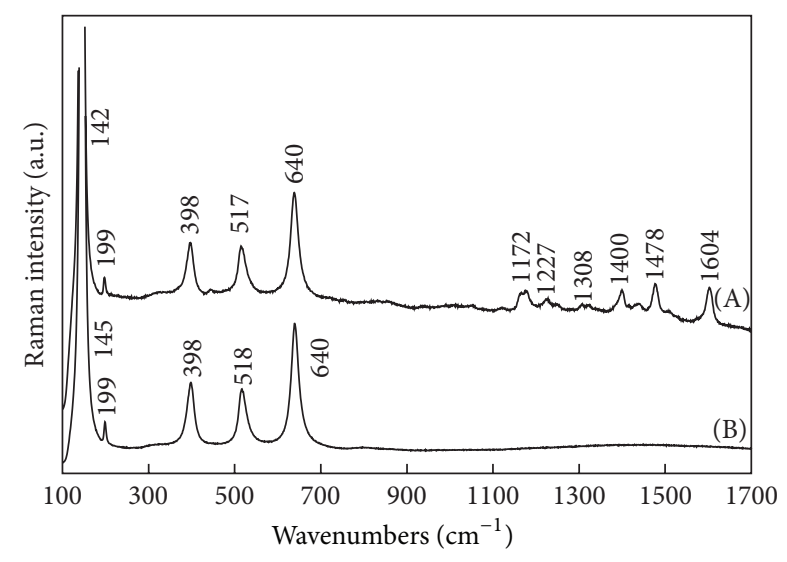

(a)

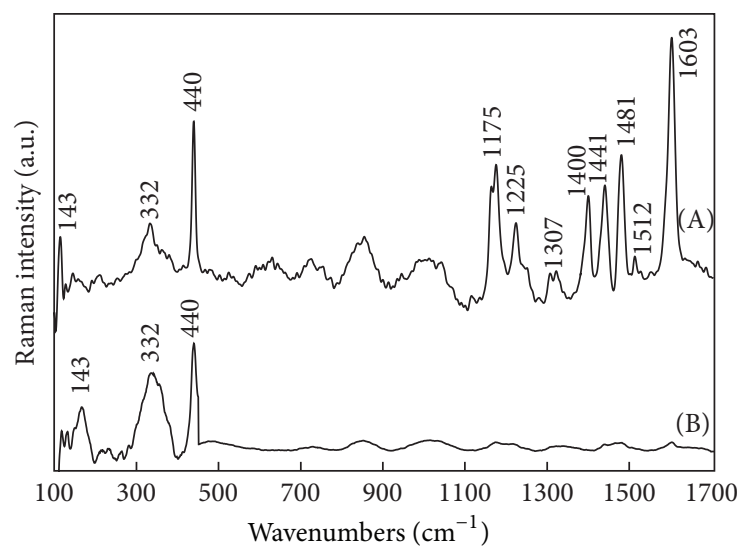

(b)

Figure 4: Raman spectra of $\mathrm{TiO}_{2}$ (a.A) and $\mathrm{ZnO}$ (b.A) after adsorption of DY9 and after 2 hours of irradiation under solar simulated light ((a.B) and (b.B), for $\mathrm{TiO}_{2}$ and $\mathrm{ZnO}$, resp.).

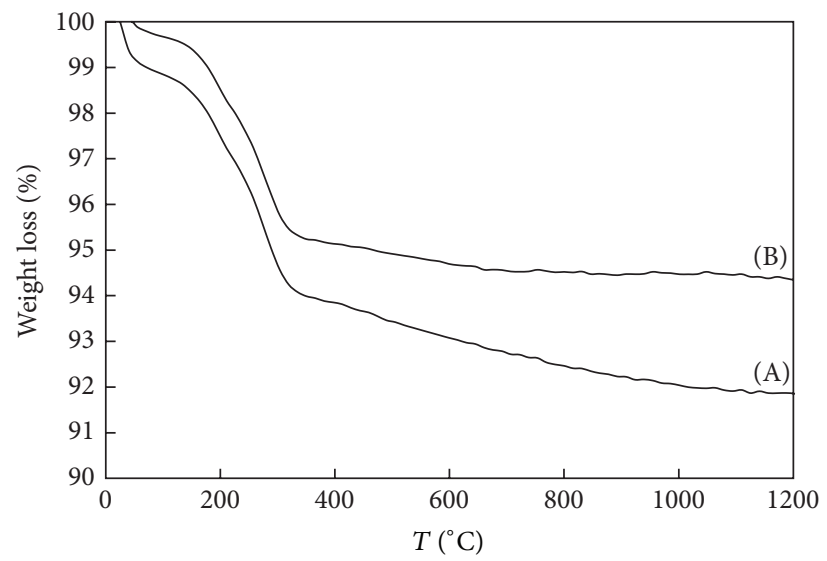

(a)

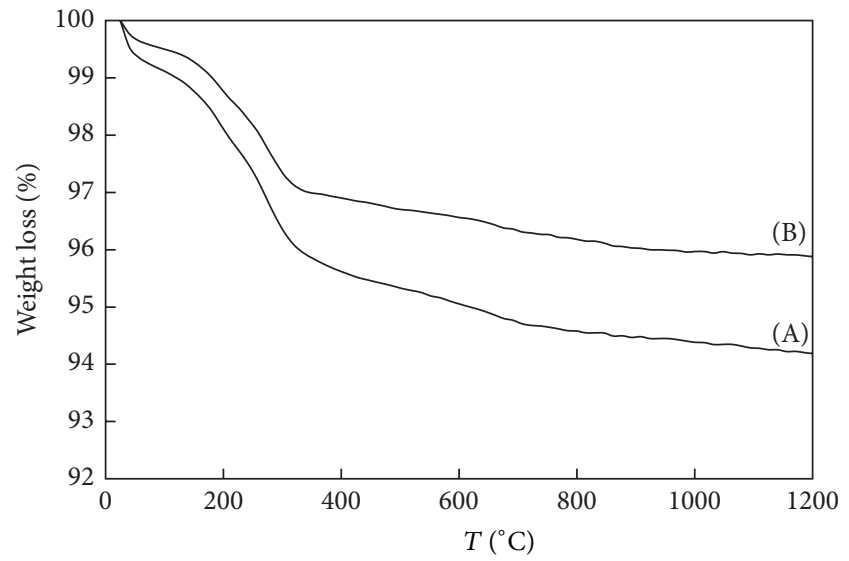

(b)

Figure 5: TGA curves of $\mathrm{TiO}_{2}$ (a) and $\mathrm{ZnO}$ (b) after adsorption of DY9 (A) and after 2 hours of irradiation under solar simulated light (B). 


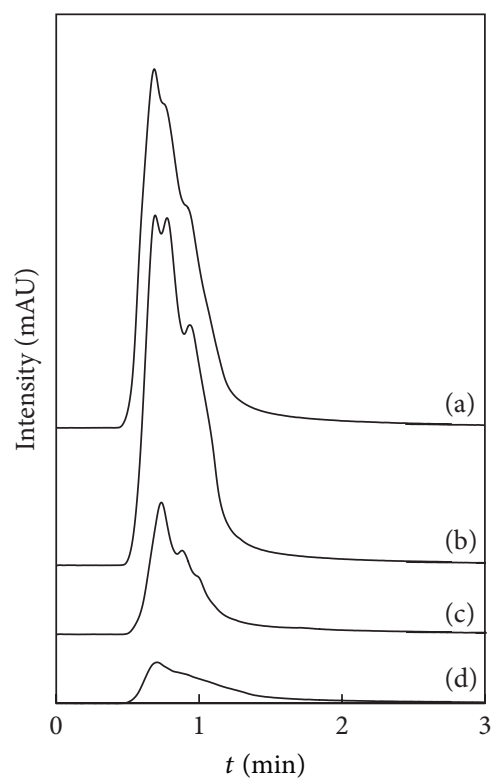

FIGURE 6: Chromatograms of DY9 (a) before and after 2 hours of irradiation under solar simulated light without (b) and with addition of $\mathrm{TiO}_{2}$ (c) and $\mathrm{ZnO}(\mathrm{d})$.

that even same photolysis of DY9 led to a slight decomposition of a dye since a tiny change in a peak shape was observed. However, only after addition of a photocatalyst a significant decrease in a peak height was noticed. HPLC analyses showed that photodegradation efficiency was more than two times bigger when $\mathrm{ZnO}$ was applied in comparison with the results obtained with $\mathrm{TiO}_{2}$.

HPLC analyses are in a good agreement with Raman microscopy as well as thermogravimetry results. They all indicate that $\mathrm{ZnO}$ leads to the higher photodegradation efficiency in comparison with $\mathrm{TiO}_{2}$.

\subsection{Optimalisation of the Studied Process}

3.4.1. Effect of Dye Concentration. Many reports [26, 27] have indicated that the kinetic model for heterogeneous photocatalysis follows the Langmuir-Hinshelwood kinetic expression:

$$
-\frac{d[\mathrm{TitY}]}{d t}=\frac{k K_{\mathrm{TitY}}[\mathrm{TitY}]_{0}}{1+K_{\mathrm{TitY}}[\mathrm{TitY}]_{0}}=k_{\mathrm{app}}[\mathrm{TitY}]_{0},
$$

where $[\mathrm{DY} 9]_{0}$ is the initial concentration of DY9 $[\mathrm{mol} / \mathrm{L}]$, $K_{\text {DY9 }}$ is Langmuir-Hinshelwood adsorption equilibrium constant $[\mathrm{L} / \mathrm{mol}], k$ is rate constant of the surface reaction [mol/L-min], $k_{\text {app }}$ is pseudofirst-order rate constant.

A linear expression can be conventionally obtained by plotting the reciprocal initial rate constant against initial concentration:

$$
\frac{1}{k_{\mathrm{app}}}=\frac{1}{k K_{\mathrm{DY} 9}}+\frac{[\mathrm{DY} 9]_{0}}{k} .
$$

The effect of initial DY9 concentration on the initial rate of degradation is shown in Figure 7. The figure indicates that
TABLE 1: Pseudofirst-order rate constants $k_{\text {app }}$ and half-live times $t_{1 / 2}$ for photocatalytic degradation of DY9 upon irradiation with solar simulated light $\left(500 \mathrm{~W} / \mathrm{m}^{2}\right)$ at varying DY9 concentration.

\begin{tabular}{lcccc}
\hline $\begin{array}{l}\text { DY9 concentration/ } \\
\mu \mathrm{mol} \cdot \mathrm{L}^{-1}\end{array}$ & $\begin{array}{c}\mathrm{TiO}_{2}\left(1.5 \mathrm{~g} \cdot \mathrm{L}^{-1}\right) \\
k_{\text {app }} / \mathrm{min}^{-1}\end{array}$ & $t_{1 / 2} / \mathrm{min}$ & $k_{\text {app }} / \mathrm{min}^{-1}$ & $t_{1 / 2} / \mathrm{min}$ \\
\hline 10 & 0.0758 & 9 & 0.0989 & 7 \\
30 & 0.0314 & 22 & 0.0669 & 10 \\
50 & 0.0312 & 22 & 0.0491 & 14 \\
80 & 0.0226 & 31 & 0.0300 & 23 \\
100 & 0.0180 & 39 & 0.0250 & 28 \\
\hline
\end{tabular}

TABLE 2: Pseudofirst-order rate constants $k_{\text {app }}$ and half-live times $t_{1 / 2}$ for photocatalytic degradation of DY $9\left(80 \mu \mathrm{mol} \cdot \mathrm{L}^{-1}\right)$ upon irradiation with solar simulated light $\left(500 \mathrm{~W} / \mathrm{m}^{2}\right)$ at varying catalysts loading $\left(\mathrm{g} \cdot \mathrm{L}^{-1}\right)$.

\begin{tabular}{lcccc}
\hline \multirow{2}{*}{ Catalyst loading/g. $\mathrm{L}^{-1}$} & \multicolumn{2}{c}{$\mathrm{TiO}_{2}$} & \multicolumn{2}{c}{$\mathrm{ZnO}$} \\
& $k_{\mathrm{app}} / \mathrm{min}^{-1}$ & $t_{1 / 2} / \mathrm{min}$ & $k_{\mathrm{app}} / \mathrm{min}^{-1}$ & $t_{1 / 2} / \mathrm{min}$ \\
\hline 0.1 & 0.0032 & 217 & 0.0049 & 141 \\
0.5 & 0.0059 & 117 & 0.0124 & 56 \\
1.0 & 0.0109 & 63 & 0.0138 & 50 \\
1.5 & 0.0226 & 31 & 0.0300 & 23 \\
\hline
\end{tabular}

for both photocatalysts, the rate of decomposition increases with the increasing initial concentration of DY9 which corresponds to Langmuir-Hinshelwood adsorption model. According to (5), $1 / k_{\text {app }}$ versus [DY9] $]_{0}$, as shown in the inset in Figure 7, gives a linear relationship. From the values of the slope $1 / k$ and the intercept $1 / k K_{\mathrm{DY}}, k$ and $K_{\mathrm{DY} 9}$ values for the photocatalytic degradation of DY9 were found to be, respectively, $\mathrm{mol} / \mathrm{L} \cdot \mathrm{min}$ and $\mathrm{L} / \mathrm{mol}$.

Integration of (4) (with the restriction of $C=C_{0}$ at $t=0$ ) will lead to the following relation:

$$
\ln \frac{C_{0}}{C_{t}}=k_{\mathrm{app}} t .
$$

The plot of $\ln \left(C_{0} / C_{t}\right)$ versus $t$ was used for the estimation of the pseudofirst-order rate constant, $k_{\mathrm{app}}$, and the halflife, $t_{1 / 2}$, of the photocatalytic degradation of DY9 (Table 1). The decrease of $k_{\text {app }}$ and increase of $t_{1 / 2}$ were observed, while DY9 concentration was rising. All the subsequent photolytic as well as photocatalytic degradation experiments were performed using $80 \mu \mathrm{M}$ DY9 solutions.

3.4.2. Effect of Catalyst Loading. The influence of the catalyst loading on the photodegradation process was studied. Kinetic values $\left(k_{\text {app }}\right.$ and $\left.t_{1 / 2}\right)$ at varying catalysts loading were calculated and presented in Table 2 . An increase of $k_{\text {app }}$ with a decrease of $t_{1 / 2}$ values was observed when the catalysts loading was increased. Following these observations, the amount of $\mathrm{TiO}_{2}$ and $\mathrm{ZnO}$ was kept constant at the optimal load of $1.5 \mathrm{~g} / \mathrm{L}$ in all the subsequent photocatalytic degradation experiments.

3.4.3. Effect of $p H$. The influence of initial $\mathrm{pH}$ on the rate of photocatalytic degradation was studied in the $\mathrm{pH} 2,7$, 


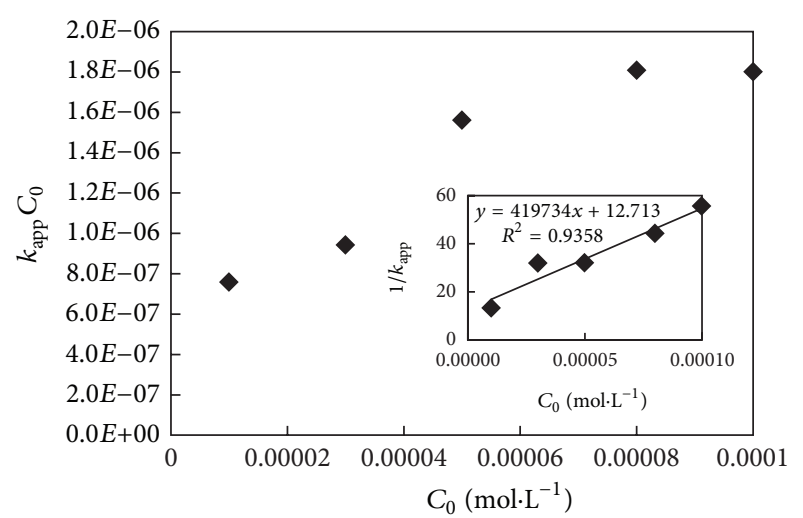

(a)

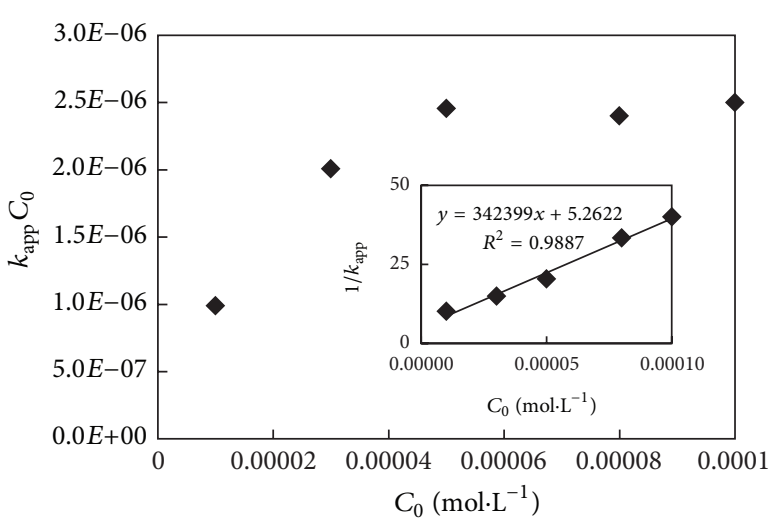

(b)

FIgURE 7: Effect of initial DY9 concentration on the initial rate of degradation with the usage of $\mathrm{TiO}_{2}$ (a) and $\mathrm{ZnO}$ (b). The inset represents the plot of $1 / k_{\text {app }}$ versus initial concentration of DY9. The photocatalysts loading was kept constant $\left(1.5 \mathrm{~g} \cdot \mathrm{L}^{-1}\right)$.

and 10 at constant dye concentration $\left(80 \mu \mathrm{mol} \cdot \mathrm{L}^{-1}\right)$ and catalyst amount $\left(1.5 \mathrm{~g} \cdot \mathrm{L}^{-1}\right)$. The results presented in Table 3 showed that the $\mathrm{pH}$ significantly affected the degradation efficiency for both semiconductors. It was observed that the rate of degradation decreased with an increase in $\mathrm{pH}$ when $\mathrm{TiO}_{2}$ was applied, whereas in the case of $\mathrm{ZnO}$, it was observed reversely. The rate of degradation increased with an increase in $\mathrm{pH}$, exhibiting maximum rate constant at $\mathrm{pH} 10$. Findings of others [28] also showed this trend. Differences between $\mathrm{TiO}_{2}$ and $\mathrm{ZnO}$ may result from different zero point charge (zpc) values, which are equal to 4.5 [29] and 9.0 [30] for $\mathrm{TiO}_{2}$ and $\mathrm{ZnO}$, respectively. The $\mathrm{pH}$ is related to the ionization state of the surface in the following way:

$$
\begin{gathered}
\mathrm{M}-\mathrm{OH}+\mathrm{H}^{+} \longleftrightarrow{\mathrm{M}-\mathrm{OH}_{2}{ }^{+}}_{\mathrm{M}-\mathrm{OH}+\mathrm{OH}^{-}} \longleftrightarrow \mathrm{MO}^{-}+\mathrm{H}_{2} \mathrm{O}
\end{gathered}
$$

Therefore photocatalysts surface is positively charged below $\mathrm{pH}_{\mathrm{zpc}}$, whereas it is negatively charged when $\mathrm{pH}>$ $\mathrm{pH}_{\mathrm{zpc}}$. This phenomenon strongly affects the adsorption process, which for anionic compounds is maximum in acidic conditions, while for cationic is maximum in basic. Since DY9 belongs to the anionic dyes, it should be strongly attached to the positively charged photocatalyst surface. However, photocatalytic degradation efficiency of $\mathrm{ZnO}$ was observed to be the highest at alkaline $\mathrm{pH}$, even though the adsorption of DY9 should be lower in this conditions. Nevertheless, this relation was also observed by others $[16,31]$ when another anionic dye (Acid Brown 14) was examined. It is thought that in alkaline $\mathrm{pH}$, where a large amount of $\mathrm{OH}^{-}$ions is present, $\mathrm{OH}^{*}$ radicals are favorably created and can significantly enhance the photocatalytic degradation of a dye.

3.4.4. Effect of $\mathrm{HCO}_{3}{ }^{-}$and $\mathrm{CO}_{3}{ }^{2-}$ Anions. The content of carbonate and bicarbonate ions in an aqueous environment of performed photocatalytic experiments was examined and found to have a negative influence on a decomposition of DY9. As presented in Table 4, rate constants decreased and half-live times increased when carbonate buffer was present
TABLE 3: Pseudofirst-order rate constants $k_{\text {app }}$ and half-live times $t_{1 / 2}$ for the photocatalytic degradation of DY9 $\left(80 \mu \mathrm{mol} \cdot \mathrm{L}^{-1}\right)$ at different initial $\mathrm{pH}$.

\begin{tabular}{lcccc}
\hline $\mathrm{pH}$ & \multicolumn{2}{c}{$\mathrm{TiO}_{2}$} & \multicolumn{2}{c}{$\mathrm{ZnO}$} \\
& $k_{\mathrm{app}} / \mathrm{min}^{-1}$ & $t_{1 / 2} / \mathrm{min}$ & $k_{\mathrm{app}} / \mathrm{min}^{-1}$ & $t_{1 / 2} / \mathrm{min}$ \\
\hline 2 & 0.0282 & 25 & 0.0133 & 52 \\
7 & 0.0226 & 31 & 0.0300 & 23 \\
10 & 0.0183 & 38 & 0.0349 & 20 \\
\hline
\end{tabular}

TABLE 4: Influence of an addition of carbonate buffer on pseudofirstorder rate constants $k_{\text {app }}$ and half-live times $t_{1 / 2}$ of the photocatalytic degradation of DY9 $\left(80 \mu \mathrm{mol} \cdot \mathrm{L}^{-1}\right)$.

\begin{tabular}{cccc}
\hline & Addition of carbonate buffer & $k_{\text {app }} / \mathrm{min}^{-1}$ & $t_{1 / 2} / \mathrm{min}$ \\
\hline $\mathrm{TiO}_{2}$ & - & 0.0226 & 31 \\
& + & 0.0147 & 47 \\
$\mathrm{ZnO}$ & - & 0.0300 & 23 \\
& + & 0.0172 & 40 \\
\hline
\end{tabular}

in the irradiated suspension of DY9 and photocatalyst. The possible reason for this behaviour is that carbonate and bicarbonate ions react with $\mathrm{HO}^{*}$ forming less active radicals, as follows:

$$
\begin{gathered}
\mathrm{CO}_{3}{ }^{2-}+\mathrm{HO}^{\bullet} \longrightarrow \mathrm{CO}_{3}{ }^{--}+\mathrm{HO}^{-} \\
\mathrm{HCO}_{3}{ }^{-}+\mathrm{HO}^{\bullet} \longrightarrow \mathrm{HCO}_{3}{ }^{\bullet}+\mathrm{HO}^{-}
\end{gathered}
$$

\section{Conclusions}

DY9 was found to be resistant to the photolytic decomposition in aqueous environment, but it undergoes the photocatalytic degradation in suspension of both examined photocatalysts, namely $\mathrm{TiO}_{2}$, and $\mathrm{ZnO}$. Two hours of irradiation upon solar simulated light led to the total decomposition of DY9 when $\mathrm{ZnO}$ was applied. In summary, we revealed the potential application of heterogeneous photocatalysis for DY9 removal from aquatic environment. Therefore, the current 
research can be considered as a step towards the commercialization of the photocatalytic removal of DY9 from the aqueous environment.

\section{Acknowledgments}

The authors kindly acknowledge the financial support from the National Science Centre, Poland (project 2012/05/N/ ST5/01479). Thermogravimeter and Raman microscope were funded by EU, as part of the Operational Programme Development of Eastern Poland 2007-2013, Project no. POPW.01.03.00-20-034/09-00.

\section{References}

[1] S. K. Asl, S. K. Sadrnezhaad, M. K. Rad, and D. Üner, "Comparative photodecolorization of red dye by anatase, rutile $\left(\mathrm{TiO}_{2}\right)$, and wurtzite $(\mathrm{ZnO})$ using response surface methodology," Turkish Journal of Chemistry, vol. 36, no. 1, pp. 121-135, 2012.

[2] E. Forgacs, T. Cserháti, and G. Oros, "Removal of synthetic dyes from wastewaters: a review," Environment International, vol. 30, no. 7, pp. 953-971, 2004.

[3] M. A. Rauf and S. S. Ashraf, "Fundamental principles and application of heterogeneous photocatalytic degradation of dyes in solution," Chemical Engineering Journal, vol. 151, no. 1-3, pp. 10-18, 2009.

[4] M. H. Habibi, A. Hassanzadeh, and S. Mahdavi, "The effect of operational parameters on the photocatalytic degradation of three textile azo dyes in aqueous $\mathrm{TiO}_{2}$ suspensions," Journal of Photochemistry and Photobiology A, vol. 172, no. 1, pp. 89-96, 2005.

[5] C. Chen, "Photocatalytic degradation of azo dye reactive orange 16 by $\mathrm{TiO}_{2}$," Water, Air, and Soil Pollution, vol. 202, no. 1-4, pp. 335-342, 2009.

[6] C. T. Fragoso, R. Battisti, C. Miranda, and P. C. de Jesus, "Kinetic of the degradation of C.I. Food Yellow 3 and C.I. Food Yellow 4 azo dyes by the oxidation with hydrogen peroxide," Journal of Molecular Catalysis A, vol. 301, no. 1-2, pp. 93-97, 2009.

[7] M. R. Sohrabi and M. Ghavami, "Photocatalytic degradation of Direct Red 23 dye using $\mathrm{UV} / \mathrm{TiO}_{2}$ : effect of operational parameters," Journal of Hazardous Materials, vol. 153, no. 3, pp. 1235-1239, 2008.

[8] N. M. Mahmoodi, M. Arami, N. Y. Limaee, and N. S. Tabrizi, "Kinetics of heterogeneous photocatalytic degradation of reactive dyes in an immobilized $\mathrm{TiO}_{2}$ photocatalytic reactor," Journal of Colloid and Interface Science, vol. 295, no. 1, pp. 159$164,2006$.

[9] S. K. Kansal, M. Singh, and D. Sud, "Studies on photodegradation of two commercial dyes in aqueous phase using different photocatalysts," Journal of Hazardous Materials, vol. 141, no. 3, pp. 581-590, 2007.

[10] W. L. Kostedt IV, A. A. Ismail, and D. W. Mazyc, "Impact of heat treatment and composition of $\mathrm{ZnO}-\mathrm{TiO}_{2}$ nanoparticles for photocatalytic oxidation of an azo dye," Industrial and Engineering Chemistry Research, vol. 47, no. 5, pp. 1483-1487, 2008.

[11] R. B. M. Bergamini, E. B. Azevedo, and L. R. R. de Araújo, "Heterogeneous photocatalytic degradation of reactive dyes in aqueous $\mathrm{TiO}_{2}$ suspensions: decolorization kinetics," Chemical Engineering Journal, vol. 149, no. 1-3, pp. 215-220, 2009.
[12] E. Bizani, K. Fytianos, I. Poulios, and V. Tsiridis, "Photocatalytic decolorization and degradation of dye solutions and wastewaters in the presence of titanium dioxide," Journal of Hazardous Materials, vol. 136, no. 1, pp. 85-94, 2006.

[13] W. Lin, W. Yang, and S. Jheng, "Photocatalytic degradation of dyes in water using porous nanocrystalline titanium dioxide," Journal of the Taiwan Institute of Chemical Engineers, vol. 43, no. 2, pp. 269-274, 2012.

[14] D. Gümüş and F. Akbal, "Photocatalytic degradation of textile dye and wastewater," Water, Air, and Soil Pollution, vol. 216, no. 1-4, pp. 117-124, 2011.

[15] R. J. Tayade, P. K. Surolia, R. G. Kulkarni, and R. V. Jasra, "Photocatalytic degradation of dyes and organic contaminants in water using nanocrystalline anatase and rutile $\mathrm{TiO}_{2}$," Science and Technology of Advanced Materials, vol. 8, no. 6, pp. 455-462, 2007.

[16] C. F. Klingshirn, "ZnO: material, physics and applications," ChemPhysChem, vol. 8, no. 6, pp. 782-803, 2007.

[17] S. Sakthivel, B. Neppolian, M. V. Shankar, B. Arabindoo, M. Palanichamy, and V. Murugesan, "Solar photocatalytic degradation of azo dye: comparison of photocatalytic efficiency of $\mathrm{ZnO}$ and $\mathrm{TiO}_{2}$," Solar Energy Materials and Solar Cells, vol. 77, no. 1, pp. 65-82, 2003.

[18] F. W. Heaton, "Determination of magnesium by the Titan yellow and ammonium phosphate methods," Journal of Clinical Pathology, vol. 13, pp. 358-360, 1960.

[19] C. Pallavicini, "Determination of magnesium in tissue by the Titan yellow method in the presence of silver and mercury," Proceedings of the Society for Experimental Biology and Medicine, vol. 110, pp. 235-237, 1962.

[20] A. H. Cornfield and A. G. Pollard, "Use of titan yellow for the determination of magnesium in plant material," Journal of the Science of Food and Agriculture, vol. 1, pp. 357-358, 1950.

[21] R. Meyrowitz, "The direct spectrophotometric microdetermination of high-level magnesium in silicate minerals," American Mineralogist, vol. 49, pp. 769-777, 1964.

[22] G. Hong-Wen and Z. Peng-Fei, " $\beta$-correction spectrophotometric determination of beryllium in waste water with titan yellow," Analytical Proceedings including Analytical Communications, vol. 31, no. 3, pp. 85-87, 1994.

[23] W. Mingxia, L. Zhongfang, H. Xiaoli, L. Shaopu, and K. Ling, "Study on the interaction of aminoglycoside antibiotics with Titan Yellow by spectrophotometric method and their analytical applications," Frontiers of Chemistry in China, vol. 2, pp. 170-173, 2006.

[24] X. Wei, Z. Liu, and S. Liu, "Resonance Rayleigh scattering spectra of tetracycline antibiotic-Cu(II)-titan yellow systems and their applications in analytical chemistry," Analytical and Bioanalytical Chemistry, vol. 385, no. 6, pp. 1039-1044, 2006.

[25] H. J. Kuhn, S. E. Braslavsky, and R. Schmidt, "Chemical actinometry (IUPAC technical report)," Pure and Applied Chemistry, vol. 76, no. 12, pp. 2105-2146, 2004.

[26] C. Martínez, M. Canle L, M. I. Fernández, J. A. Santaballa, and J. Faria, "Kinetics and mechanism of aqueous degradation of carbamazepine by heterogeneous photocatalysis using nanocrystalline $\mathrm{TiO}_{2}, \mathrm{ZnO}$ and multi-walled carbon nanotubes-anatase composites," Applied Catalysis B, vol. 102, no. 3-4, pp. 563-571, 2011.

[27] H. R. Pouretedal and A. Kadkhodaie, "Synthetic $\mathrm{CeO}_{2}$ nanoparticle catalysis of methylene blue photodegradation: kinetics and mechanism," Chinese Journal of Catalysis, vol. 31, no. 11, pp. 1328-1334, 2010. 
[28] S. Naskar, S. A. Pillay, and M. Chanda, "Photocatalytic degradation of organic dyes in aqueous solution with $\mathrm{TiO}_{2}$ nanoparticles immobilized on foamed polyethylene sheet," Journal of Photochemistry and Photobiology A, vol. 113, no. 3, pp. 257-264, 1998.

[29] C. Wu and J. Chern, "Kinetics of photocatalytic decomposition of methylene blue," Industrial and Engineering Chemistry Research, vol. 45, no. 19, pp. 6450-6457, 2006.

[30] Elaziouti, N. Laouedj, and B. Ahmed, "ZnO-mediated photocatalytic degradation of Benzopurpurine BP4B in aqueous solution," Journal of Chemical Engineering \& Process Technology, vol. 2, pp. 1-9, 2011.

[31] F. Zhang, J. Zhao, T. Shen, H. Hidaka, E. Pelizzetti, and N. Serpone, " $\mathrm{TiO}_{2}$-assisted photodegradation of dye pollutants II. Adsorption and degradation kinetics of eosin in $\mathrm{TiO}_{2}$ dispersions under visible light irradiation," Applied Catalysis B, vol. 15, no. 1-2, pp. 147-156, 1998. 

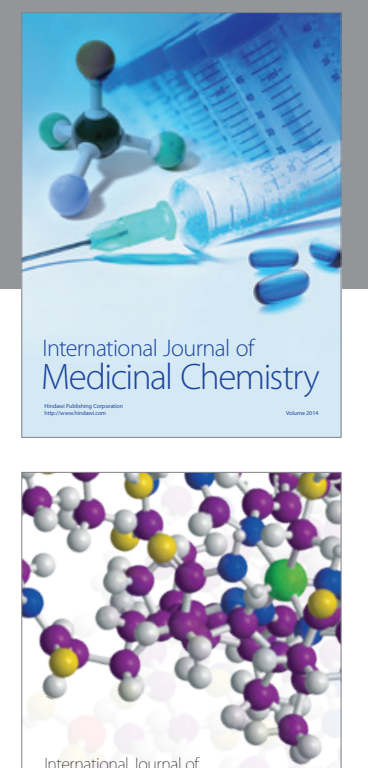

\section{Carbohydrate} Chemistry

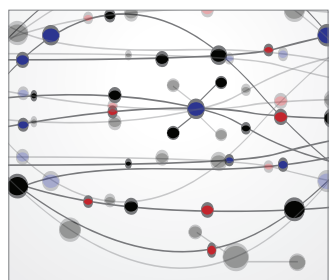

The Scientific World Journal
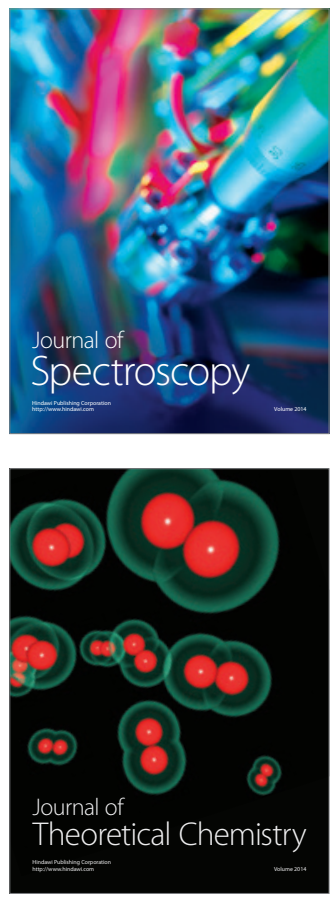
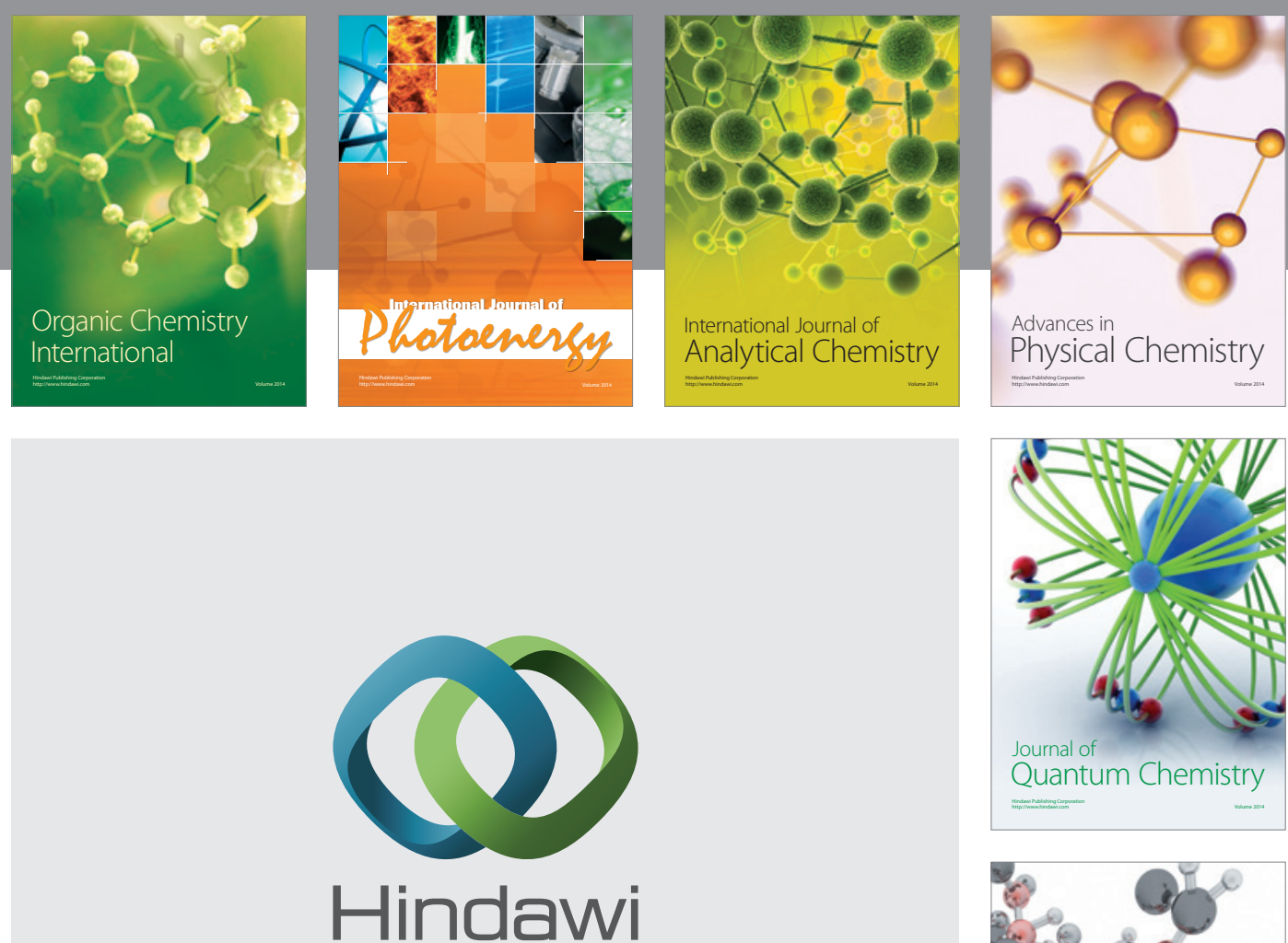

Submit your manuscripts at

http://www.hindawi.com

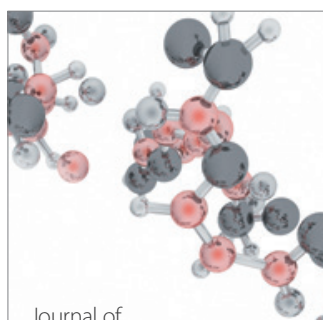

Analytical Methods

in Chemistry

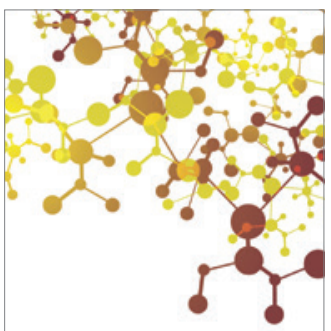

Journal of

Applied Chemistry

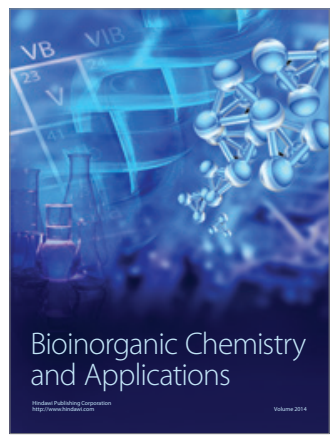

Inorganic Chemistry
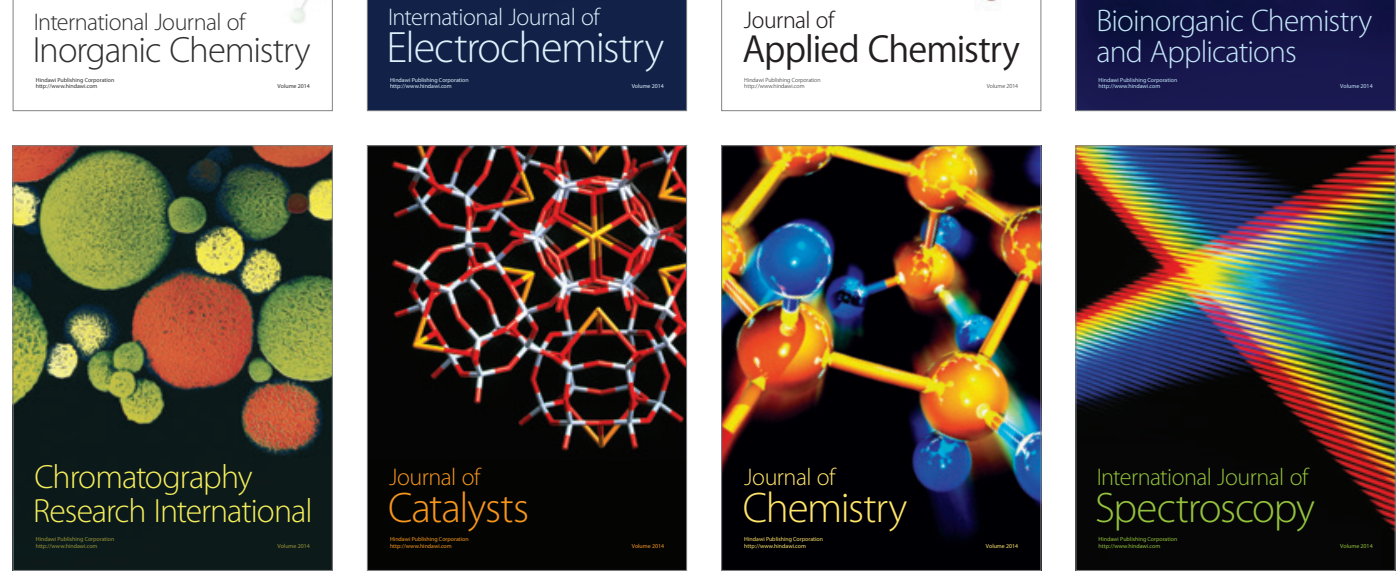